\title{
Measuring to Manage Electronic Commerce Technology: Estimating The Return On E-Commerce Technology
}

\author{
Thomas J.Housel \\ Professor
}

\begin{abstract}
For investment in electronic commerce, evidence has shown that businesses have difficulty in evaluating when to use information technology and how to measure its economic benefits. Solving this basic problem is essential for business and government decision makers as they apply promising new electronic commerce technology to improve their organizations' performance. This paper will review the literature pertaining to the problem of measuring impact of information technology on firm performance, suggest KVA as a way to address gaps in the literature, and provide a case analysis to demonstrate how KVA can be applied in a practical way. We conclude with a discussion of the requirements for any theoretical framework attempting to assess the value of electronic commerce technology, including KVA, as well as a how such approaches can help management redesign core processes using this new technology.
\end{abstract}

Keywords: Knowledge Measurement, Knowledge Management, KVA, Knowledge, ValueAdded, E-commerce

\section{INTRODUCTION}

For investment in electronic commerce, evidence has shown that businesses have difficulty in evaluating when to use information technology and how to measure its economic benefits. Solving this basic problem is essential for business and government decision makers as they apply promising new electronic commerce technology to improve their organizations' performance.

\footnotetext{
The original version of this chapter was revised: The copyright line was incorrect. This has been corrected. The Erratum to this chapter is available at DOI: 10.1007/978-0-387-35617-4_48 
There have been numerous approaches to assessing the impact of information technology on firm economic performance at the corporate and sub-corporate levels. A theoretical framework that would unify analysis to address this problem at any level of aggregation has yet to emerge. In what follows, we will review the literature pertaining to the problem of measuring impact of information technology on firm performance, suggest KVA as a way to address gaps in the literature, and provide a case analysis to demonstrate how KVA can be applied in a practical way. We conclude with a discussion of the requirements for any theoretical framework attempting to assess the value of electronic commerce technology, including KVA, as well as a how such approaches can help management redesign core processes using this new technology.

\section{LITERATURE REVIEW}

Academics and practitioners alike have attempted to address the issue of how to compute the return on information technology (Stewart, 1997; Strassman, 1997). This research is of particular relevance to the problem of calculating a return on electronic commerce technology since this technology is a subset of information technology (IT).

\section{Corporate Level}

The corporate level approaches to measuring the value added by IT are accounted for and income proportionately reduced, the remainder is asserted to be revenue attributable to knowledge capital and/or information technology (Strassman, 2000A; 2000B; 2000C). Following this approach, all costs attributable to all cost categories except electronic commerce technology would reduce the income proportionately leaving the income attributable to the electronic commerce technology.

Others use production theory to determine the various contributions of inputs to the firm's output. The resulting "production function" (Brynjolfsson and Hitt, 1996 , p. 545) can be modeled using economic theory to determine the unique contributions of IT with computer capital, noncomputer capital, information systems staff labor and other labor expenses as the inputs (which represent all spending by the organization as well as all capitalized investment) and output in terms of dollars or physical units. This neoclassical economic theory of production treats firms as "black boxes" (Brynjolfsson and Hitt, 1996, p. 544) 
and attempts to deduce the relationship between inputs and outputs without reference to activities within the firm.

Various criticisms have been leveled at these approaches including that the research using these approaches does not "adequately control for other factors [i.e., other than information technology] that drive firm profits" (Bharadwaj, 2000, p. 170). Strassman (1997) indicated that using typical aggregate level financial ratios, or variations thereof, offer no help in attempting to determine the relationship between investments in IT and a company's economic performance.

One suggestion for addressing these shortcomings offered by Brynjolfsson and Hitt (1996, p. 557) would be to account for the value added by IT via "intangible outputs such as product quality or variety." The problem with this approach is that it does not posit a common unit of analysis that would allow allocation of revenue to IT making it impossible to generate an unambiguous connection between IT and the value it adds.

In light of the problems in information technology (IT) investment decision making, the application of option pricing models (OPMs) has attracted increasing attention recently. Benaroch and Kauffman (1999) investigated the value of applying real options analysis in the context of a case study involving the deployment of point-of-sale debit services by an electronic banking network. One of the significant contributions from this research is the establishment of a formal theoretical grounding for the validity of the option pricing model in the context of the spectrum of capital budgeting methods that might be employed to assess IT investments. However, some implicit assumptions in using this model may potentially limit the validity of the analysis, such as, using net present value in OPM used in the calculation of risk requires an assumption about projected cash-flow. There is no cash-flow directly attributable to corporate core processes since the outputs of those processes are not salable without the outputs of all the other core processes.

Researchers using the resource-based view attempt to overcome the shortcomings of the prior methodologies for estimating the value added by IT by linking a firm's performance to IT resources that are firm-specific such as knowledge, capabilities and unique core processes (Bharadwaj, 2000; Jarvenpaa and Leidner, 1998). The assumption is that these unique resources and capabilities are difficult, and very expensive, to copy and therefore provide competitive advantages leading to superior economic returns. A limitation of this view is that it does not posit a common unit of analysis that would allow an unambiguous linkage between a firm's use of IT and the firm's performance, and therefore, it would be difficult to unambiguously determine the specific 
contribution of a given electronic commerce technology initiative to the firm's performance.

\section{Sub-corporate Level}

These approaches use a wide variety of methods to assess the contribution of IT to firm performance focusing analyses at the process or activity level in an attempt to determine the contribution of IT to a firm's performance. Two representative approaches include replacement cost and family of measures. The potential and limitations of the sub-corporate level methods for assessing the value added by IT are reviewed in this session.

Many of the cost-based approaches use underlying replacement cost (e.g., transfer pricing, internal markets, outsourcing) or cost of activities (e.g., activitybased costing approaches) to determine the economic impact of information technology (Housel and Bell, 2001). These approaches assume that the cost of IT is in some way proportionate to its value. Other approaches assume that by allowing corporate managers to negotiate the transfer price of IT services with each other to meet their unit's goals, that the price is representative of the IT's underlying value.

The generic limitation of these approaches is the fact that if cost is used as a surrogate for value, then all the information is contained in one term of the ratio, i.e., the denominator. Conceptually, when performance ratios are used to measure the benefits of a given IT initiative, it would be illogical to use the same data source (i.e., cost and its variants) for both the numerator and denominator. The data source for value should come from the revenue side of the firm's performance (i.e., numerator) and the data source for cost (i.e., denominator) should come from the cost to produce the firm's outputs. A method for evaluating the specific contributions of an electronic commerce initiative should be able to unambiguously allocate revenue to the initiative in proportion to its contribution.

The family of measures approach researchers advocate the need to measure multiple indicators to derive the unique contributions of information technology (e.g., Edvinsson and Malone, 1997; Kaplan and Norton, 1996). The Balanced Scorecard provides for typically from four to five key performance indicators selected by management to determine the success of a given strategic organizational thrust. In the case of an electronic commerce initiative, the organization's management team might select this initiative for assessment via a key performance indicator, such as level of customer satisfaction. 
Edvinsson and Malone's (1997) Intellectual Capital Navigator allows a firm to identify up to 140 variables that account for the performance of its intangible assets including IT (i.e., a subset of its infrastructure assets). Examples of these measures would include: laptops/employee, IT expense/employee, IT staff/staff total, IT literacy of employees, and so on (Edvinsson and Malone's, 1997, p. 109).

The limitation of these approaches is that they do not provide a common theoretical framework that ties investments in electronic commerce IT unambiguously to a firm's economic performance (Bharadwaj, 2000). A theoretical framework robust enough to solve this problem must be able to account for IT's contribution by allocating revenue directly to the electronic commerce technology deployed throughout a firm. It would then be possible to calculate a return on investment-based ratio for this technology.

\section{KNOWLEDGE VALUE-ADDED: OVERVIEW}

KVA provides a theoretical framework that enables allocation of revenue to electronic commerce initiatives in proportion to the economic value they add. The framing assumption of KVA is that businesses are open systems that exchange information, substance, and energy with their environments. As such, businesses have the capability, through a series of intermediate steps (i.e., their processes), to change the structure of raw material inputs (i.e., substance, energy, information) into outputs (e.g., final products/services). The purpose of businesses is to produce value via their processes (El Sawy, 2001).

The changes these processes make in the structure of inputs to produce outputs can be described in a common way in terms of the entropy concept borrowed from thermodynamics. The concept of entropy is defined as a measure of the degree of disorder or change in a system. In the context of e-business processes it is used as a surrogate for process change. These process induced changes can be measured in terms of the equivalent corresponding changes in entropy, when an input state $\boldsymbol{a}$ is transformed into output state $\boldsymbol{b}$ by process $\boldsymbol{P}$ (i.e., $b=P(a)$ ).

The entropy concept can used to establish a measure of the common units of change executed by business processes that have predetermined outputs. If the resulting total amount of change in entropy is a representation of the total output of the business via its processes, it follows that the amount of entropy can be used as a surrogate for the revenue generated by the outputs. Because the entropy formulation allows measurement of the changes in common units, it 
then becomes possible to allocate revenue in proportion to the amount of change in entropy at any level of aggregation in a company.

Further, a change in entropy when state $\boldsymbol{a}$ is transformed into state $\boldsymbol{b}$ depends only on $\boldsymbol{a}$ and $\boldsymbol{b}$ and does not depend on process $\boldsymbol{P}$. This means that any process $\boldsymbol{P}$ that changes $\boldsymbol{a}$ into $\boldsymbol{b}$ introduces the same change in entropy or, in a business context, adds the same value. It follows that introducing changes to a process, through electronic commerce IT for example, that do not produce changes in the process output ( for example in terms of its frequency, cost, qualities, characteristics), add no value.

It is reasonable to assume that the minimal set of instructions to change $a$ into $\boldsymbol{b}$, via process $\boldsymbol{P}$ reflects the corresponding change in entropy given the current state of process $\boldsymbol{P}$. In other words, the length of the shortest description of the change provides an acceptable approximation to the change in entropy given the current state of the process. This becomes critical in recognizing that estimations of changes in entropy can only ever be approximations.

For example, one programmer could automate a process using 4000 lines of code and another could do it using 400 lines of code with the process output being exactly the same. The lines of code can be seen as surrogates for the changes the process executes to produce the output and therefore, proportionate to changes in entropy. However, following the shortest description rule for purposes of estimating changes in entropy, it is the 400 line program that would serve as the shortest description referred to above.

It is also important to point out that theoretically it impossible to create the shortest description. This is important in recognizing that any estimate is prone to some level of error. Therefore the shortest description rule is used for guidance in estimating the amount of change executed by any process. This issue is particularly relevant when checking the reliability of estimates of change in entropy in real world operationalizations of KVA.

The relationship between change in entropy and value added, while fundamental, does not provide a practical way to calculate the value-added by process $\boldsymbol{P}$, i.e., the entropy increment. A knowledge management framework provides a practical solution to this problem. The knowledge required to make process changes provides a practical surrogate for the corresponding changes in entropy.

This framework can be applied to the context of e-commerce IT that support business processes. E-commerce business processes may be described in terms of the of knowledge assets used to produce their outputs. Those e-commerce process knowledge assets are distributed in people and IT. It follows, that the knowledge used by these process assets to produce the attendant outputs may be viewed as a surrogate for the process outputs. 
The business process outputs, when combined produce revenue. It follows, that the knowledge required to produce those outputs is a surrogate for the revenue. Further, if this knowledge can be described in equivalent units, then it is possible to allocate the corporate revenue to these units of knowledge. This would allow establishment of a price per unit of knowledge. It follows that price per unit of knowledge is a surrogate for price per common unit of output. This formulation allows a direct linkage between corporate revenue and the knowledge distributed among the people and IT used to produce the revenue.

Hence it would be possible to establish the proportionate revenue produced by the knowledge in processes including the knowledge contained in the supporting e-commerce IT. This would make it possible to estimate, subsequent to determining the cost to use the knowledge, the return on that knowledge (ROK). ROK is a ratio with the percentage of revenue allocated to a core process based on the amount of knowledge required to produce the process' outputs in the numerator and the cost to use the knowledge in the denominator. ROK in this sense can be used at any level of aggregation to estimate return on IT.

A proof-of-concept case is in order to demonstrate the practical operationalization of the KVA approach to measuring the return on knowledge embedded in e-commerce IT.

\subsection{KVA Application: Exodus Communications, Inc.}

This case example is meant to provide a context for a discussion of how KVA can be applied to assess the performance of corporate knowledge assets and method for assessing the potential return provided by a specific electronic commerce initiative designed to improve the sales process. 


\section{Assumptions and Methodology}

The KVA team interviewed process subject matter experts (SMEs), made observations, and talked with process employees and managers to obtain average learning-time estimates and the number of roughly equivalent process instructions required to complete each sub-process. Some of the numbers for the analysis, such as, number of employees and expenses, were annualized figures derived from the 1999 financial statement. The following steps (Table 1) were taken to select a process for improvement using electronic commerce technology.

\section{Implications for Measuring ROK on Electronic Commerce Technology}

The sales provisioning process was one of the core processes that offered promise for the application of electronic commerce technology for two reasons. The sales provisioning process included six sub-processes: sales support \& design, service selection \& NAD, procurement, integration, trouble-shooting and final testing. A KVA analysis was conducted on the sales provisioning process and the steps in this analysis are represented below. 
Step one- Identify sub-processes. The Exodus sales provisioning process involved six subprocesses (Table 2, Column 1).

Step two - Establish a common definition of learning time and process instructions. We asked the SMEs to estimate how long it would take an "average" person to learn to produce the subprocess outputs. The learning time estimate indicated that a total of approximately 2000 weeks were required to learn the whole sequence of how to execute each subprocess. We asked the subject matter experts to describe the process instructions for producing the outputs of the six subprocesses which totaled 2,120 instructions. Because the correlation between the two knowledge estimates was $89 \%$, only the learning time estimates were used for the calculation of the ROKs for the subprocesses (Table 2 - Column 2).

Step three - Multiply the learning time for each subprocess by the number of employees to estimate the number of times the subprocess knowledge executed on an annualized basis. We multiplied the number of employees (column 3 ) by the learning time (column 2 ). Then we added the percentage of automation (column 4) to derive the total amount of knowledge used in the subprocess (column 5). The total percentage of knowledge is proportionately allocated to each subprocess in column 6 and the total amount of revenue for each subprocess is also allocated in column 7.

Step four- Calculate the cost to execute each sub-process based on the assumption that the total of twenty-two worldwide data centers share the same cost structure as a typical one in El Segundo. This assumption was checked for accuracy in further discussions with the appropriate subject matter experts and executives. The annual cost for each subprocess is represented in Column 8. In this case, the primary determinant of cost was the employees working in each area and this was used to allocate cost with other general expenses (real estate, equipment, power, etc.) equally divided among the subprocesses.

Step five - Compute the ROKs for each subprocess using revenue allocated for each subprocess (Column 7) as the numerator and cost for each subprocess (Column 8) for the denominator. The resulting returns on knowledge are represented in Column 9. 


\begin{tabular}{|c|c|c|c|c|c|c|c|c|}
\hline $\begin{array}{l}\text { ub-process } \\
\text { Column } 1\end{array}$ & $\begin{array}{l}\text { Learning } \\
\text { Time } \\
\text { Weeks) } \\
\text { Column } 2\end{array}$ & $\begin{array}{l}\text { Yo. Or } \\
\text { Employees } \\
\text { Column } 3 \\
\end{array}$ & $\begin{array}{l}\text { Amount of } \\
\text { Knowledge } \\
\text { Embedded in } \\
\mathrm{rT} \\
(35 \%) \\
\text { Column } 4 \\
\end{array}$ & $\begin{array}{l}\text { Total } \\
\text { Amount of } \\
\text { knowledge } \\
\text { Column } 5\end{array}$ & $\begin{array}{l}\text { Percentage } \\
\text { of } \\
\text { Knowledge } \\
\text { Allocation } \\
\text { Column } 6 \\
\end{array}$ & $\begin{array}{l}\text { Annual } \\
\text { Revenue } \\
\text { Allocation } \\
\text { (in } \\
\text { millions) } \\
\text { Column } 7 \\
\end{array}$ & $\begin{array}{l}\text { Process } \\
\text { Costs (in } \\
\text { millions) } \\
\text { Column } 8\end{array}$ & $\begin{array}{l}\mathrm{ROK} \\
\mathrm{Col} .9\end{array}$ \\
\hline Sales & 240 & 8 & 672 & 2,592 & $15 \%$ & $\$ 13.7$ & $\$ 12.2$ & \\
\hline \begin{tabular}{|l|} 
Service \\
Selection \& \\
NAD
\end{tabular} & 400 & 8 & 1,120 & 4,320 & $25 \%$ & $\$ 22.8$ & $\$ 24.3$ & \\
\hline Procurement & 60 & 5 & 105 & 405 & $2.5 \%$ & $\$ 2.3$ & $\$ 3$ & \\
\hline Integration & 500 & 5 & 875 & 3,375 & $20 \%$ & $\$ 18.3$ & $\$ 20.3$ & \\
\hline \begin{tabular}{|l|}
$\begin{array}{l}\text { Trouble } \\
\text { Shooting }\end{array}$ \\
\end{tabular} & 500 & 6 & 1,050 & 4,050 & $23.5 \%$ & $\$ 21.4$ & $\$ 19$ & \\
\hline Final Testing & 300 & 6 & 630 & 2,430 & $14 \%$ & $\$ 12.8$ & $\$ 6.4$ & \\
\hline Total & 2000 & 38 & & 17,172 & $100 \%$ & $\$ 91.3$ & $\$ 85.2$ & \\
\hline
\end{tabular}

Table 2: KVA On The Sales Provisioning Process

\section{The Proposed Electronic Commerce Initiative}

The team proposed that Exodus management move much of the sales knowledge required to service smaller accounts into an Internet-based threetiered electronic commerce information system. This would enable the separation of large and preferred clients from small clients with simpler needs, so that the sales force could spend their time focusing on up-selling and making sure the needs of the preferred clients were met. The small clients would be able to complete the purchase of standardized services without the assistance of a salesperson or engineer via the electronic commerce information system.

The proposed e-commerce based information systems solution would allow NAD design jobs to be transferred to design engineers in different locations via an intranet that engineers in multiple locations could use to collaborate on network design/problem solving. The electronic commerce system could offer customers on-line project status checking and tracking of NAD and equipment procurement providing customers a direct and timely update of their project status.

These changes to the current distribution of knowledge within the sales provisioning processes would enable a greater number of orders, simple and complex, to be processed increasing revenue. Large and small customers could use the knowledge that was redistributed to the new system more frequently alike, thus increasing the overall amount of knowledge executed in an annual period. 
The transfer of knowledge to the new systems would increase sales by including an untapped market segment and would reduce the cost for the use of knowledge embedded in the systems designed to service this segment. The order status checking feature of the new system would also service the existing large customer base. The precise improvement in process parameters could be specified in much finer detail but the purpose here was to demonstrate how KVA could be applied to the problem of determining the potential return on such an electronic commerce system initiative.

Table 3 provides a sample solution including the return on knowledge and return on process estimates (ROP). The ROP estimates are derived using the process instructions method of estimating the amount of change in each subprocess area. The correlation among the learning time and process instruction estimates $(96 \%)$ is an simple reliability estimate. The ROK/ROP estimates for the return on the proposed electronic commerce IT indicated that initiative had tremendous potential in adding value to the sales-provisioning process.

The case was meant to be illustrative of the practical use of KVA to project the potential return that e-commerce technology might have in enabling the redesign of business processes. Given that the proposed process redesign initiative would enable the execution of a large amount of knowledge resulting in increased sales and for a relatively low cost, the return on this e-commerce IT would justify proceeding with the initiative.

\section{CONCLUSIONS}

KVA is but one potential theoretical framework that researchers interested in measuring the impacts of electronic commerce initiatives at all levels of aggregation might use to focus their efforts. It offers the advantages of positing a common unit of analysis that allows allocation of revenue as well as cost enabling the development of ratios to measure and model the returns on IT initiatives.

As in any theoretical frameworks, KVA has a number of limitations. It was expressly designed for processes with predetermined outputs. This makes it problematic for measuring inherently creative processes, such as research and development. However, much of the R\&D function is relatively routinized in many companies. In addition, the outputs of $R \& D$ to be of value to firms must eventually find their way into core processes with predetermined outputs. In this way, it is possible to use KVA to track the conversion of such creative outputs into value as they are embedded in processes with predetermined outputs. 
Much work needs to be done to find a common language of description of knowledge in e-commerce processes, including the supporting information technology. For now, it is expedient to rely on multiple estimates of knowledge using the process instructions and learning time approaches to check the reliability of knowledge estimates.

The most significant benefit of this paper may be to offer some common requirements that any theoretical approach should meet to be accepted as a means to determine the benefits of electronic commerce initiatives to firm's performance. Providing managers with a practical, valid and reliable way to estimate the return on electronic commerce initiatives is only a beginning.

\begin{tabular}{|c|c|c|c|c|c|c|c|c|c|}
\hline $\begin{array}{l}\text { Sub- } \\
\text { process }\end{array}$ & \begin{tabular}{|l|} 
Learning \\
Time - LT \\
(Weeks)
\end{tabular} & \begin{tabular}{|l} 
LT \\
Value \\
Added \\
$(\$)$
\end{tabular} & $\begin{array}{l}\text { Process } \\
\text { Instruc- } \\
\text { tions } \\
\text { PI* }\end{array}$ & $\begin{array}{l} \\
\text { PI- Value } \\
\text { Added }\end{array}$ & $\begin{array}{l}\text { Subprocess } \\
\text { Execution } \\
\text { Time (months) }\end{array}$ & $\begin{array}{l}\text { Monthly } \\
\text { Rate }\end{array}$ & \begin{tabular}{|l} 
Process \\
Costs
\end{tabular} & ROK & ROP \\
\hline Sales & 180 & $\$ 41,337$ & 190 & $\$ 36,052$ & 0.8 & $\$ 7,700$ & $\$ 5,775$ & $716 \%$ & $624 \%$ \\
\hline \begin{tabular}{|l|} 
Service \\
Select \& \\
NAD
\end{tabular} & 220 & $\$ 50,523$ & 230 & $\$ 43,642$ & 3.6 & $\$ 3,840$ & $\$ 13,824$ & $365 \%$ & $316 \%$ \\
\hline $\begin{array}{l}\text { Procure- } \\
\text { ment }\end{array}$ & 105 & $\$ 24,113$ & 140 & $\$ 26,565$ & 2.4 & $\$ 1,920$ & $\$ 4,608$ & $523 \%$ & $576 \%$ \\
\hline $\begin{array}{l}\text { Integra- } \\
\text { tion }\end{array}$ & 825 & $\$ 189,461$ & 810 & $\$ 153,697$ & 20.0 & $\$ 2,880$ & $\$ 57,600$ & $329 \%$ & $267 \%$ \\
\hline $\begin{array}{l}\text { Trouble } \\
\text { Shoot-ing }\end{array}$ & 650 & $\$ 149,272$ & 690 & $\$ 130,927$ & 22.5 & $\$ 3,600$ & $\$ 81,000$ & $184 \%$ & $162 \%$ \\
\hline $\begin{array}{l}\text { Final } \\
\text { Testing }\end{array}$ & 750 & $\$ 172,237$ & 620 & $\$ 117,644$ & 10.0 & $\$ 4,800$ & $\$ 48,000$ & $359 \%$ & $245 \%$ \\
\hline $\begin{array}{l}\text { Propos-ed } \\
\text { E-Com IT } \\
\text { initiative }\end{array}$ & 1,550 & $\$ 355,957$ & 2,500 & $\$ 474,373$ & 0.3 & $\$ 8,000$ & $\$ 2,400$ & $\begin{array}{l}14832 \\
\%\end{array}$ & $\begin{array}{l}19766 \\
\%\end{array}$ \\
\hline Sum & 4,280 & $\$ 982,900$ & 5,180 & $\$ 982,900$ & 59.6 & & $\$ 213,207$ & $461 \%$ & $461 \%$ \\
\hline
\end{tabular}
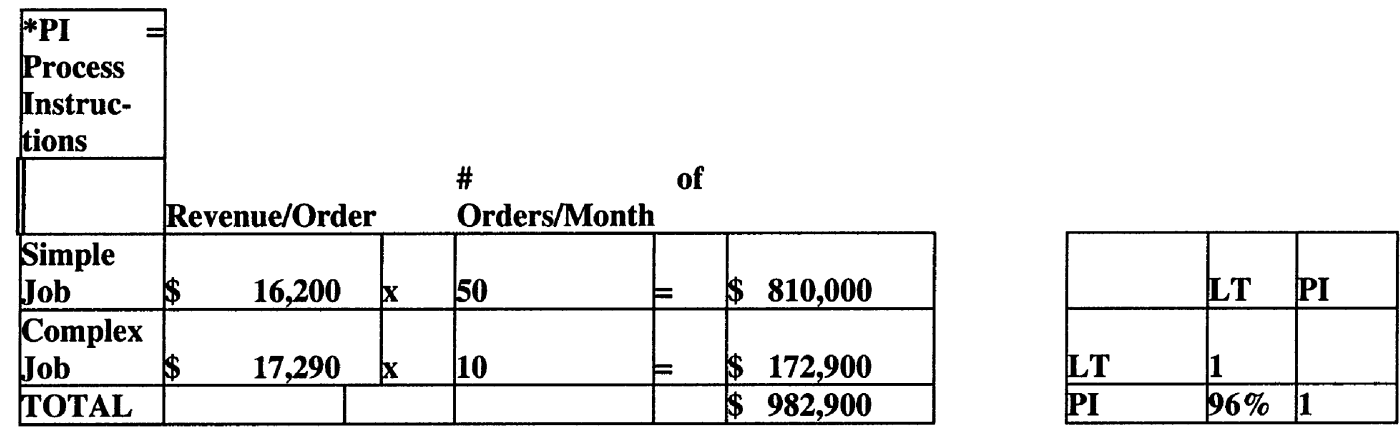

Table 3: Proposed Electronic Commerce Initiative ROK Estimates for the Sales-Provisioning Process 


\section{REFERENCES}

Benaroch, M. and R. J. Kauffman, "A case for Using Real Options Pricing Analysis to Evaluate Information Technology Project Investments", Information Systems Research, March (1999), $70-86$.

Bharadwaj, Anandhi, S., "A Resource-Based Perspective on Information Technology Capability and Firm Performance: An Empirical Investigation," MIS Quarterly, March (2000), 169-196.

Brynjolfsson, Erik, and Hitt, Lorin., "Paradox Lost? Firm-level Evidence on the Returns on Information Systems Spending," Management Science, April (1996), 541-558.

Edvinsson, Leif and Malone, Michael, S., Intellectual Capital, Harper Business, New York, 1997.

Housel, Thomas J. and Bell Arthur A., Managing and Measuring Knowledge, McGraw-Hill, Boston, 2001.

Housel, Thomas and Hom, Sandra. Knowledge Management for the Telecommunications Industry, Professional Education International, Inc., International Engineering Consortium, Chicago, 1999.

Housel, Thomas J. and Kanevsky, Valery, A., "Re-Engineering Business Processes: A Complexity Theory Approach to Value Added", Information Systems and Operational Research (1995), 248-262.

Jarvenpaa, Sirkka, L., and Leidner, Dorothy. E., "An Information Company in Mexico: Extending the Resource-based View of the Firm to a Developing Country Context," Information Systems Research, December (1998), 342-361.

Kaplan, Robert and David Norton., The Balanced Scorecard, Harvard Business School Press, Boston, 1996.

Rodgers, Financial Statement Analysis: Informational and Modeling Perspectives. Houghton Mifflin, in press

Stewart, Thomas A., Intellectual Capital: The New Wealth Of Organizations, Double Day, New York, 1997.

Strassman, Paul, A. The Squandered Computer, The Information Economics Press, New Haven, 1997.

Strassman, Paul, A., “Accumulating Knowledge Efficiency," Knowledge Management, February (2000)

"The Knowledge-Devouring Web," Knowledge Management, April (2000)

"Prices, Finances and Knowledge Capital," Knowledge Ma 